\title{
Protection of DDAH2 Overexpression Against Homocysteine-Induced Impairments of DDAH/ADMA/NOS/NO Pathway in Endothelial Cells
}

\author{
Li-Hua Liu ${ }^{b}$ Zheng Guo ${ }^{b, d}$ Mei Feng ${ }^{b, d} \quad$ Zhong-Zu Wu $u^{b, d}$ Zhi-Min He ${ }^{c}$ Yan Xiong,b \\ Department of Pharmacology, a'Guangzhou Research Institute of Snake Venom, Guangzhou Medical \\ University, Guangzhou, Guangdong; 'bSchool of Pharmaceutical Sciences, Central South University, \\ Changsha, Hunan; 'Cancer Research Institute, Cancer Hospital, Guangzhou Medical University, \\ Guangzhou, Guangdong; P.R. China; 'Equally contributed to this project
}

\section{Key Words}

Homocysteine - Asymmetric dimethylarginine - Dimethylarginine dimethylaminohydrolase • Gene transferring • Nitric oxide

\begin{abstract}
Background/Aims: Homocysteine-induced endothelial dysfunction favors the development of cardiovascular diseases through accumulation of endogenous nitric oxide (NO) synthase (NOS) inhibitor asymmetric dimethylarginine (ADMA). Dimethylarginine dimethylaminohydrolase 2 (DDAH2) is the major enzyme for the degradation of ADMA in endothelial cells. The purpose of this study was to determine whether suppressed DDAH2 expression contributed to impairments of DDAH/ADMA/NOS/NO pathway induced by homocysteine in endothelial cells and whether DDAH2 overexpression could prevent endothelial cell dysfunction caused by homocysteine. Methods: Liposome-mediated transfection of endothelial cells was performed to establish the cell line of DDAH2 overexpression. After treatment of cells with $1 \mathrm{mmol} / \mathrm{L}$ homocysteine for $24 \mathrm{~h}$, the transcription and expression of DDAH1 and DDAH2, DDAH and NOS activities as well as ADMA and NO concentrations were measured. Results: Treatment of endothelial cells with homocysteine significantly suppressed the transcription and expression of DDAH2 but not DDAH1. This suppression was associated with the declined DDAH activity, increased ADMA accumulation, inhibited NOS activity and decreased NO production in endothelial cells. DDAH2 overexpression not only resisted homocysteine-induced decline of DDAH activity, but also decreased the accumulation of endogenous ADMA, subsequently attenuated the reductions of NOS activity and NO production induced by homocysteine. Conclusions: These results indicate that suppression of DDAH2 expression is a culprit for homocysteineinduced impairments of DDAH/ADMA/NOS/NO pathway in endothelial cells, and therapeutic manipulation of DDAH2 expression may be a promising strategy for preventing endothelial dysfunction and cardiovascular diseases associated with hyperhomocysteinemia.
\end{abstract}

Copyright $\odot 2012$ S. Karger AG, Basel

Yan Xiong, MD, PhD, Professor

Department of Pharmacology

Research Institute of Snake Venom, Guangzhou Medical University

$195^{*}$ Dong Feng West Road, Guangzhou 510182, Guangdong (P. R. China)

Tel. / Fax +86-020-81340352, E-Mail Xiongyan2001@yahoo.com 


\section{Introduction}

Hyperhomocysteinemia is an independent risk factor for cardiovascular diseases. It has been showed that hyperhomocysteinemia is responsible for about $10 \%$ of total risk of cardiovascular diseases [1]. Homocysteine favors the development of cardiovascular diseases through its endothelial toxicity which leads to the decrease of nitric oxide (NO) bioavailability and impairment of endothelium-dependent vasodilatation, generally termed as endothelial dysfunction [2,3]. It is well recognized that endothelial dysfunction plays a pivotal role in the pathogenesis of cardiovascular diseases. However, there is no medical treatment that is effective to prevent the endothelial dysfunction and cardiovascular diseases associated with hyperhomocysteinemia. Although supplement of vitamin B could reduce plasma homocysteine concentrations, the endothelial dysfunction induced by homocysteine could not be improved by treatment with vitamin B [4-8]. Therefore, it is important to find an effective therapeutic approach for improving endothelial dysfunction and cardiovascular diseases induced by hyperhomocysteinaemia.

Asymmetric dimethylarginine (ADMA), an endogenous inhibitor of nitric oxide synthase (NOS), has been identified as an independent risk factor of endothelial dysfunction $[2,9,10]$. Elevated ADMA concentration has been found in many cardiovascular diseases which are related to endothelial dysfunction [11-13]. In multivariable regression analysis, ADMA plasma concentrations were positively correlated with plasma total homocysteine $[10,14]$, and elevated ADMA concentration is always associated with homocysteine-induced endothelial dysfunction $[2,4,10,13,14]$. These results indicate that ADMA is a mediator of endothelial dysfunction induced by homocysteine.

The major pathway of endogenous ADMA clearance is hydrolysis to citrulline and methylamines by dimethylarginine dimethylaminohydroase (DDAH), so DDAH is the key regulator of endogenous ADMA levels. Two isoforms of DDAH, DDAH1 and DDAH2 with tissue-specific distribution have been identified. It is intriguing that DDAH activity was significantly inhibited after homocysteine treatment in endothelial cells, but DDAH protein expression remained unchanged [15]. Although homocysteine was found to inhibit the activity of DDAH directly [16], overexpression of DDAH1 could not protect the mice with dietary hyperhomocysteinemia from endothelial dysfunction [17]. These results allowed authors to speculate that DDAH2 rather than DDAH1 might play a pivotal role in ADMA metabolism of endothelial cells and homocysteine-induced endothelial dysfunction. Accordingly, in the present study, the alterations of DDAH/ADMA/NOS/NO pathway induced by homocysteine were measured in endothelial cells, and then the effects of DDAH2 overexpression on homocysteine-induced impairments of DDAH/ADMA/NOS/NO pathway in endothelial cells were subsequently investigated. The results of this study would delineate a crucial role for suppression of DDAH2 expression as a culprit event in homocysteine-induced impairments of DDAH/ADMA/NOS/NO pathway and further elucidate the mechanism for endothelial dysfunction associated with hyperhomocysteinemia.

\section{Materials and Methods}

\section{Materials}

Homocysteine, ADMA, antipyrine, diacetyl monoxime were from Sigma (St Louis, MO, USA). RPMI1640 and TRIzol were from Gibco (Gaithersburg, MD, USA). Fetal bovine serum was purchased from Sijiqing Biological Engineering Materials Co. Ltd (Hangzhou, China). AMV reverse-transcription reagents were obtained from Promega (Madison, WI, USA). Restriction endonucleases and molecular cloning reagents were from MBI (Vilnius, Lithuania). Specific PCR primers for DDAH1, DDAH2, and glyceraldehyde-3phosphate dehydrogenase (GAPDH) were synthesized by Invitrogen Biotechnologies (Shanghais, China). The polyantibody against DDAH2 or DDAH1 was purchased from Abcam (Cambridge, MA, USA). Commercial kits of NOS, nitrite/nitrate and lactate dehydrogenase (LDH) were obtained from Nanjing Jiancheng Biological Medical Engineering Institute (Nanjing, China). 
Cell culture

Human umbilical vein endothelial cell line (HUVEC, ATCC, Manassas, VA, USA) were cultured in RPMI1640 medium supplemented with $10 \%$ (v/v) fetal bovine serum and maintained at $37^{\circ} \mathrm{C}$ in a humidified atmosphere with $5 \% \mathrm{CO}_{2}$. Cells were routinely trypsinized when they reached confluence using $0.02 \%$ $(\mathrm{w} / \mathrm{v})$ EDTA and $0.25 \%(\mathrm{w} / \mathrm{v})$ trypsin. This cell line retains many characteristics of primary endothelial cells, including the expression of DDAH and NOS as well as the synthesis of NO.

\section{Experimental protocol}

The pcDNA3.1-DDAH2 expression plasmid was constructed, and the stable DDAH2-transfected endothelial cells were selected by incubation with G418 (800 $\mu \mathrm{g} / \mathrm{ml})$ for approximate 14 days as previously described [18]. DDAH2 overexpression was screened by RT-PCR and Western blotting. Subconfluent untransfected, pcDNA3.1-DDAH2 transfected and empty vector transfected cells were cultured in the absence or presence of homocysteine ( $1 \mathrm{mmol} / \mathrm{L})$ for $24 \mathrm{~h}$. After treatment, the cells were harvested for measurements of mRNA transcription and protein expression of DDAH1 and DDAH2, as well as the enzyme activities of DDAH and NOS, media were collected to determine the concentrations of ADMA, nitrite/nitrate and LDH.

\section{Determination of DDAH1/DDAH2 mRNA transcription}

Total RNA was prepared from endothelial cells after exposure to homocysteine and reversely transcribed into cDNA. DDAH1 and DDAH2 transcription were determined by RT-PCR. Primers for DDAH1 are forward 5'-GCAACTTTAGATGG CGGAGA-3' and reverse 5'-CCAGTTCAGACATGCTCACG-3' at the conditions: an initial denaturation step at $94^{\circ} \mathrm{C}$ for $5 \mathrm{~min}$, followed by 30 cycles of $94^{\circ} \mathrm{C}$ for $45 \mathrm{~s}, 55^{\circ} \mathrm{C}$ for $45 \mathrm{~s}, 72^{\circ} \mathrm{C}$ for $45 \mathrm{~s}$ and a final elongation at $72^{\circ} \mathrm{C}$ for $5 \mathrm{~min}$. Human DDAH2 specific primers are forward 5'-GATCGAATTCAGGATGGGGACGCCGGGG-3' and reverse 5'-GATCTCTAGATCAGCTGTGGGGGCGTGTG-3' following the conditions: initial denaturation at $94^{\circ} \mathrm{C}$ for $5 \mathrm{~min}$ followed by 30 cycles of denaturation $\left(94^{\circ} \mathrm{C}\right.$, $30 \mathrm{~s}$ ), annealing $\left(55^{\circ} \mathrm{C}, 30 \mathrm{~s}\right)$, extension $\left(72^{\circ} \mathrm{C}, 1 \mathrm{~min}\right)$, and a final elongation $\left(72^{\circ} \mathrm{C}, 5 \mathrm{~min}\right)$. The $\mathrm{mRNA}$ levels of DDAH1 and DDAH2 were standardized with the corresponding GAPDH as an internal control. Primers for GAPDH are forward 5'-AACTTTGGCATTGTGGAAGG-3' and reverse 5'-TGTGAGGGAGATGCTCAGTG-3'.

\section{Western blots}

Cells were lysed with RIPA buffer, and equivalent amounts of protein (assessed by the Bradford protein assay) were loaded on $10 \%$ sodium dodecyl sulfate polyacrylamide gel electrophoresis (SDS-PAGE) and the proteins were transferred onto a nitrocellulose membrane. The membranes were incubated with 5\% skimmed milk at room temperature for $1 \mathrm{~h}$, and then incubated with polyantibodies against DDAH1, DDAH2 and $\beta$-actin over night at $4^{\circ} \mathrm{C}$, followed by incubation with second goat anti-rabbit polyclonal antibody at room temperature for $1 \mathrm{~h}$, respectively. After washing again, protein bands were detected with the method of chemiluminescence and exposed to X-ray films. Densitometric quantifications of DDAH1 and DDAH2 protein bands were performed using a Bio-Rad Image Analyzer densitometry system and normalized to their corresponding $\beta$-actin protein band.

\section{Assays of DDAH, NOS and LDH activities}

Cells were resuspended in $1 \mathrm{ml}$ sodium phosphate buffer $(0.1 \mathrm{mM}, \mathrm{pH} 6.5)$ and then sonicated. The supernatant was assayed for DDAH activity by the conversion of L-citrulline from ADMA as previously described [19]. One unit of the enzyme was defined as the amount that catalyzed formation of $1 \mu \mathrm{mol} / \mathrm{L}$ L-citrulline from ADMA per min at $37^{\circ} \mathrm{C}$ and normalized to the protein content of the supernatant.

The NOS activity was assayed as previously described [18]. One unit of enzyme activity was defined as amount catalyzing formation of $1 \mathrm{nmol} / \mathrm{L} \mathrm{NO}$ from L-arginine per minute at $37^{\circ} \mathrm{C}$ and normalized to the protein content of the supernatant.

Leakage of LDH was measured as an index of cell damage by the conversion of lactic acid to pyruvic acid with a commercial assay kit. The amount of the resultant pyruvic acid was determined spectrophotometrically at $440 \mathrm{~nm}$. One unit of the enzyme activity was defined as the amount that catalyzed formation of $1 \mathrm{mmol} / \mathrm{L}$ pyruvic acid per min at $37^{\circ} \mathrm{C}$ and normalized to the cell number. Accordingly, LDH activity was expressed as units per milliliters of medium per $10^{6}$ cells. 
Fig. 1. Identification of DDAH2 overexpressing endothelial cell line. Total RNA and proteins were extracted from untransfected (Lane 1), pcDNA3.1DDAH2-transfected (Lane 2), and pcDNA3.1-transfected (Lane 3) endothelial cells. A shows the DDAH2 mRNA transcription by RT-PCR. B shows DDAH2 protein expression by Western blotting.

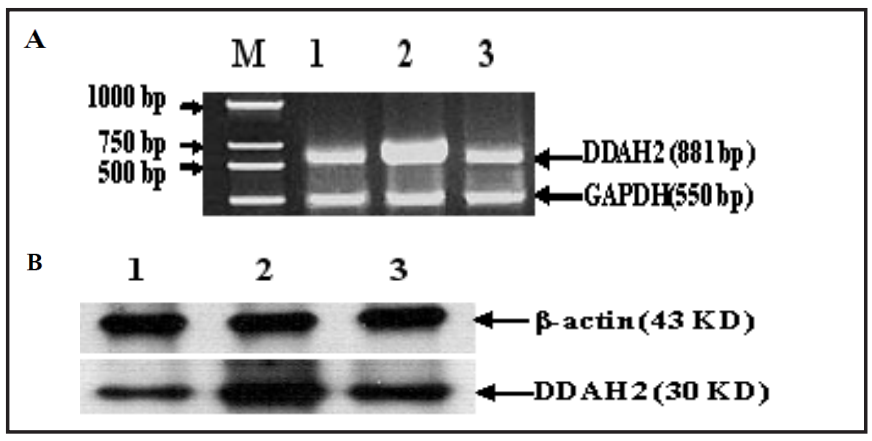

Fig. 2. Effects of DDAH2 gene transfer on DDAH2 transcription and expression in homocyteine-treated endothelial cells. Total RNA and proteins were extracted from untransfected (Lanes 1 \& 4), pcDNA3.1DDAH2-transfected (Lanes 2 \& 5), and pcDNA3.1transfected (Lanes 3 \& 6) endothelial cells treated with $(1 \mathrm{mmol} / \mathrm{L} \mathrm{Hcy})$ or without homocysteine (Control) for 24 h. A shows DDAH2 transcription by RTPCR. B is the quantification of relative DDAH2 mRNA levels vs GAPDH. C shows DDAH2 expression by Western blotting. $D$ is the quantification of relative DDAH2 protein levels vs $\beta$-actin. Data are expressed as mean \pm SEM from 3 independent experiments. ${ }^{*} P<0.05$, ${ }^{*} P<0.01$ compared with group-matched untransfected or pcDNA3.1-transfected cells; ${ }^{\sharp} P<0.05,{ }^{\#} P<0.01$ compared with the respective control group.

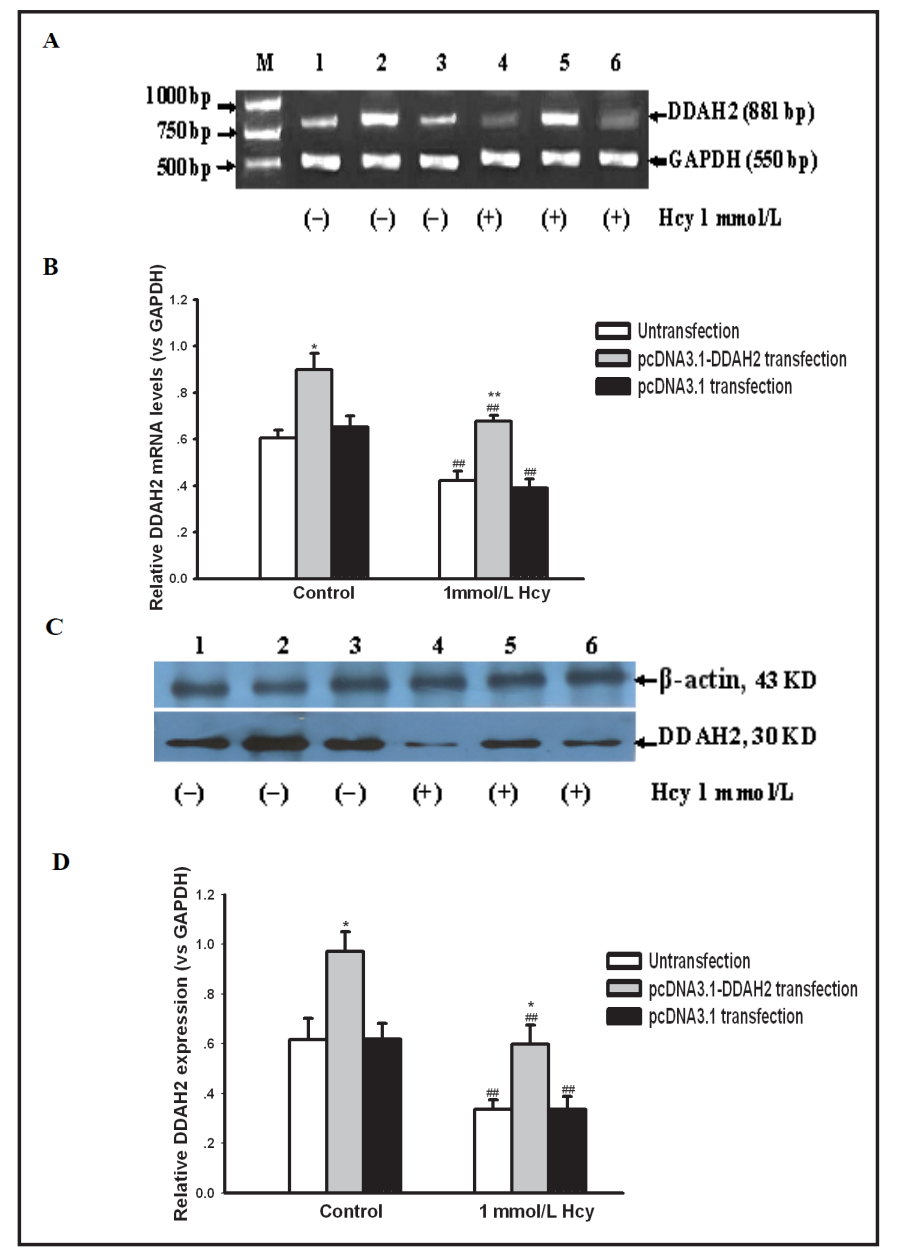

Measurement of ADMA and nitrite/nitrate concentrations

Conditioned medium was pipetted into a tube containing 5-sulfosalicylic acid, and the mixture stored at $4^{\circ} \mathrm{C}$ for 10 minutes and then centrifuged to precipitate protein. The supernatant was used for measurement of ADMA by high-performance liquid chromatography (HPLC) method [2].

Concentrations of nitrite/nitrate, the stable end products of NO were assayed as previously described [18]. Briefly, nitrate was converted to nitrite with nitrite reductase, and the total nitrite was measured with the Griess reagent.

Statistical Analysis

Data are expressed as mean \pm S.E.M. The significance of differences between groups was tested by ANOVA followed by the Newman-Keuls test. $P<0.05$ was considered as statistically significant. 
Fig. 3. Effects of DDAH2 gene transfer on DDAH1 transcription and expression in homocyteine-treated endothelial cells. Total RNA and proteins were extracted from untransfected (Lanes 1 \& 4), pcDNA3.1DDAH2-transfected (Lanes 2 \& 5), and pcDNA3.1transfected (Lanes 3 \& 6) endothelial cells treated with (1 mmol/L Hcy) or without homocysteine (Control) for 24 h. A shows DDAH1 transcription by RTPCR. B is the quantification of relative DDAH1 mRNA levels vs GAPDH. C shows DDAH1 expression by Western blotting. D is the quantification of relative DDAH1 protein levels vs $\beta$-actin. Data are expressed as mean \pm SEM from 3 independent experiments. ${ }^{*} P<0.05, \quad * * P<0.01$ compared with group-matched untransfected or pcDNA3.1-transfected cells; ${ }^{P} P<0.05$, \#\# $P<0.01$ compared with the respective

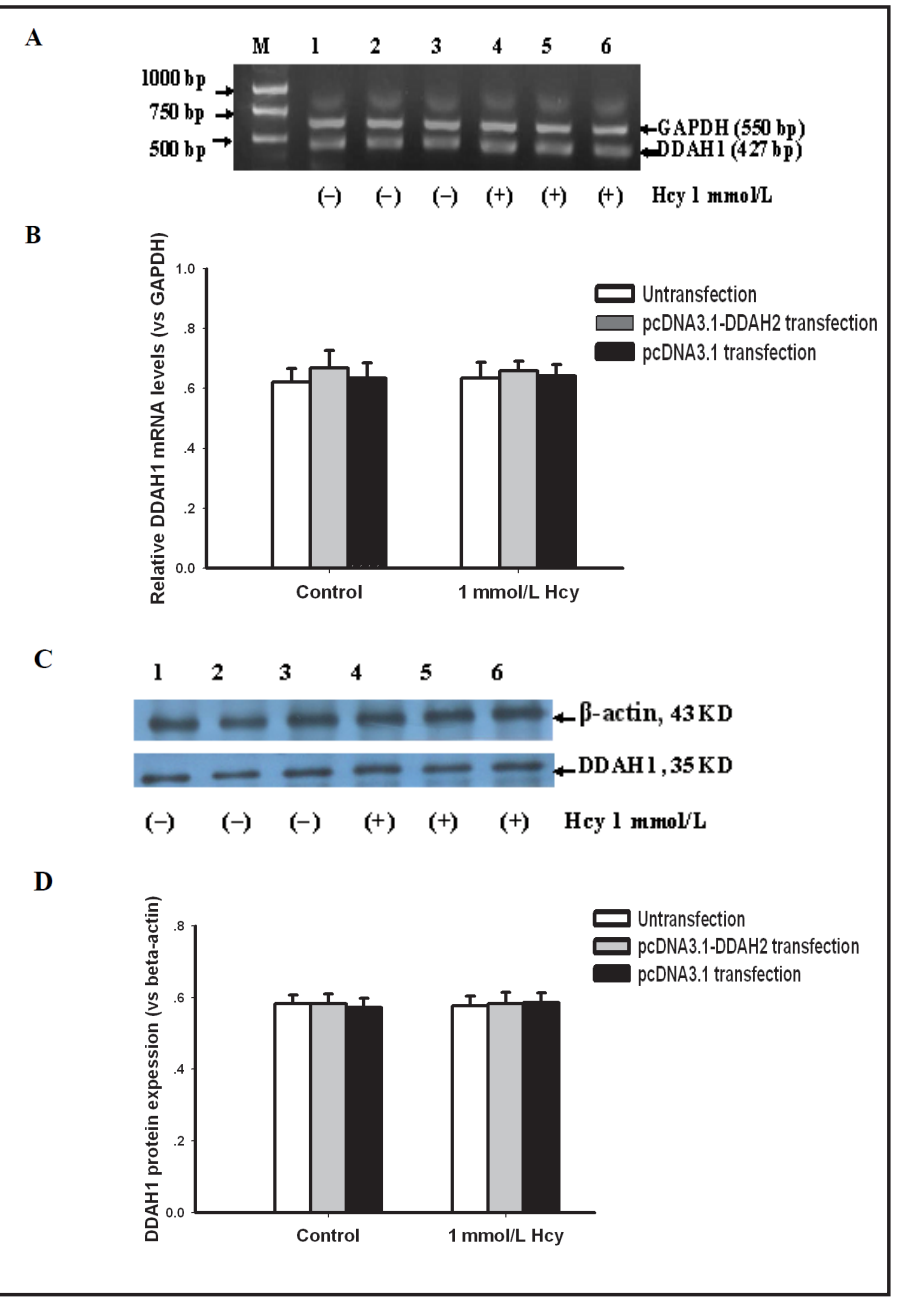

\section{Results}

\section{Construction of DDAH2 overexpressing cells}

In the present study, the end othelial cell line of DDAH2 overexpression was constructed, shown by the higher levels of DDAH2 mRNA by RT-PCR (Fig.1 A) and DDAH2 protein by Western blotting (Fig.1 B) in DDAH2-transfected cells than that in untransfected cells or empty vector transfected cells.

\section{Impairments of DDAH/ADMA/NOS/NO pathway by homocystein}

Exposure of endothelial cells to $1 \mathrm{mmol} / \mathrm{L}$ homocysteine for $24 \mathrm{~h}$ suppressed DDAH2 mRNA transcription (Fig. $2 \mathrm{~A} \& \mathrm{~B}, \mathrm{P}<0.01$ ) and protein expression (Fig. $2 \mathrm{C} \& \mathrm{D}, \mathrm{P}<0.01$ ) but did not affect DDAH1 transcription (Fig. $3 \mathrm{~A} \& \mathrm{~B}, \mathrm{P}=\mathrm{NS}$ ) or expression (Fig. $3 \mathrm{C} \& \mathrm{D}, \mathrm{P}=\mathrm{NS}$ ). In parallel with the suppression of DDAH2 expression, DDAH activity was inhibited after homocysteine incubation in endothelial cells compared with corresponding control cells without homocysteine treatment $(P<0.01$, Fig. 4 A).

Incubation of endothelial cells with homocysteine significantly enhanced the accumulation of ADMA $(P<0.01$, Fig. $4 \mathrm{~B})$ and subsequently inhibited NOS activity $(P<0.01$, Fig. $4 \mathrm{C}$ ) versus their corresponding control cells. In accordance with the alteration in NOS activity, the concentration of nitrite/nitrate, the stable end product of NO, was finally reduced in homocysteine-treated endothelial cells compared with their corresponding control without homocysteine treatment $(P<0.01$, Fig. 4 D). 


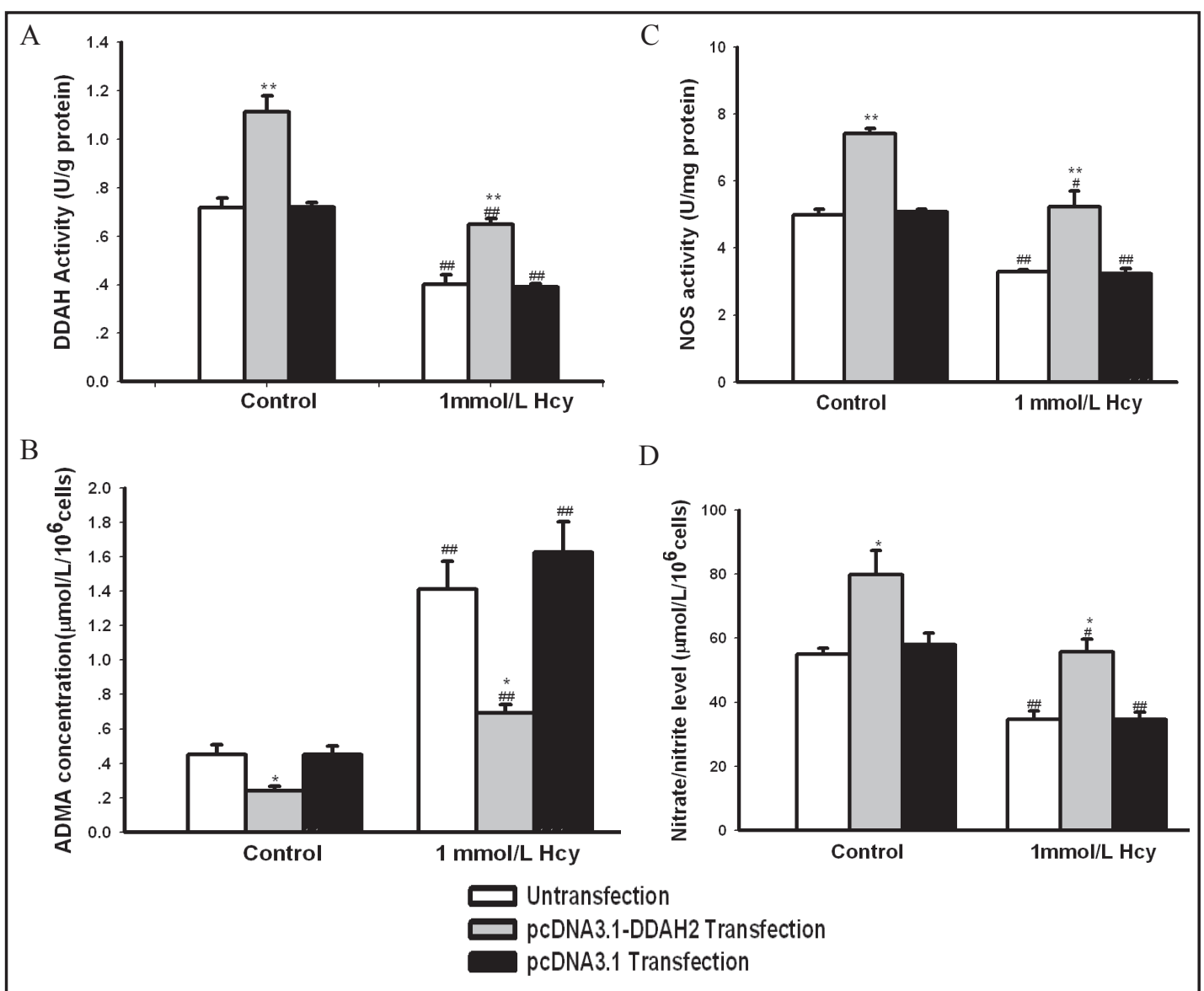

Fig. 4. Effects of DDAH2 overexpression on the pathway of DDAH/ADMA/NOS /NO in homocysteine-treated endothelial cells. Untransfected, pcDNA3.1DDAH2-transfected, and pcDNA3.1-transfected endothelial cells were treated with ( $1 \mathrm{mmol} / \mathrm{L} \mathrm{Hcy}$ ) or without homocysteine (Control) for $24 \mathrm{~h}$. A shows the DDAH activity in endothelial cells. B shows the ADMA concentration in the conditioned media of these cells. C shows the NOS activity in endothelial cells. D shows the level of nitrite/nitrate in the conditioned media of these cells. Data are expressed as mean \pm SEM from 3 independent experiments. ${ }^{*} P<0.05$, ${ }^{* *} P<0.01$ compared with the group-matched untransfected or pcDNA3.1-transfected cells. ${ }^{\#} P<0.05,{ }^{\#} P<0.01$ compared with the respective control group.

Protection against homocysteine-induced impairments of DDAH/ADMA/NOS/NO pathway by DDAH2 overexpression

As shown in figure 2, DDAH2 gene transfer not only enhanced the levels of DDAH2 mRNA and protein in endothelial cells under basal condition (Fig. 2 A $-D, P<0.05$ ), but also attenuated homocysteine-induced suppression of DDAH2 transcription and expression (Fig. $2 \mathrm{~A}-\mathrm{D}, \mathrm{P}<0.01$ ) compared to the cells with untransfection or empty vector transfection. However, DDAH1 transcription (Fig. $3 \mathrm{~A} \& \mathrm{~B}, \mathrm{P}=\mathrm{NS}$ ) and expression (Fig. $3 \mathrm{C} \& \mathrm{D}, \mathrm{P}=\mathrm{NS}$ ) was not affected by DDAH2 transfection.

Subsequently, the basal DDAH activity was increased, and homosysteine-induced inhibition of DDAH activity was diminished in DDAH2 transfected cells compared with untransfected cells $(P<0.01$, Fig. 4A). DDAH2 transfection also decreased the basal concentration of ADMA and weakened the accumulation of ADMA induced by homocysteine compared to untransfected cells $(P<0.05$; Fig. 4B).

Similarly, the basal level of NOS activity was enhanced $(P<0.01$; Fig. $4 \mathrm{C})$, and the inhibition of NOS activity due to homocysteine was attenuated by DDAH2 overexpression in comparison with untransfected cells $(P<0.01$; Fig. $4 \mathrm{C})$. In consistent with the change in 
Fig. 5. Effect of homocysteine and DDAH2 overexpression on LDH activity in the conditioned medium of cultured endothelial cells. Untransfected, pcDNA3.1DDAH2-transfected, and pcDNA3.1transfected endothelial cells were treated with (1 $\mathrm{mmol} / \mathrm{L} \mathrm{Hcy}$ ) or without homocysteine (Control) for $24 \mathrm{~h}$. The activity of lactate dehydrogenase (LDH) in the conditioned medium of these cells was measured by conversion of lactic acid to pyruvic acid. Data are expressed as mean \pm SEM from 3 independent experiments. ${ }^{*} P<0.05$ compared with the group-matched untransfected or pcDNA3.1transfected cells; ${ }^{\#} P<0.01$ compared with the respective control group.

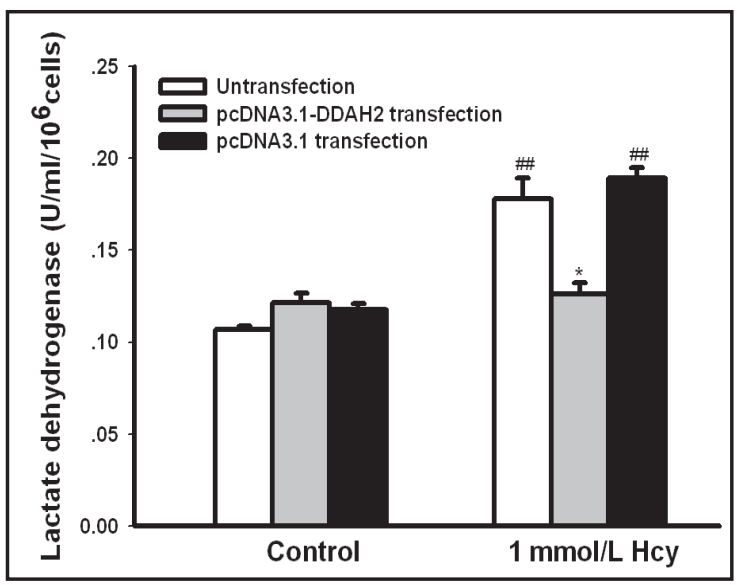

NOS activity, DDAH2 overexpression either elevated the basal production of NO reflected by the concentration of nitrite/nitrate $(P<0.05$; Fig. 4D) or dwindled the reduction of NO production induced by homocysteine $(P<0.05$; Fig. 4D). By contrast, there was no significant effect of transfection with empty plasmid on DDAH/ADMA/NOS/NO pathway in endothelial cells under basal state or homocysteine challenge compared with untransfected cells (Fig. $4 \mathrm{~A} \sim \mathrm{D})$.

Prevention of homocysteine-induced cell injury by DDAH2 overexpression

Treatment of endothelial cells with $1 \mathrm{mmol} / \mathrm{L}$ homocysteine for $24 \mathrm{~h}$ significantly increased LDH activity in either untransfected endothelial cells or empty vector transfected endothelial cells compared with their control group $(\mathrm{P}<0.01$, Fig. 5), indicating that homocysteine treatment injured endothelial cells. DDAH2 gene transfer could protect endothelial cells from the damage of homocysteine as shown by preventing the increase of LDH activity in conditional medium under homocysteine challenge compared to untransfected and empty vector transfected endothelial cells $(\mathrm{P}<0.05$, Fig. 5) but had no significant effect on LDH activity under basic state compared with untransfected group or empty vector transfected group ( $\mathrm{P}=\mathrm{NS}$, Fig. 5), suggesting that DDAH2 gene transfer enhanced the resistance of endothelial cells to homocysteine injury.

\section{Discussion}

The present study confirmed that homocysteine inhibited DDAH activity leading to the accumulation of endogenous ADMA and reduction of NO synthesis in cultured endothelial cells. More importantly, this study revealed that these inhibitory effects of homocysteine were mediated by suppression of DDAH2 transcription and expression but not DDAH1. DDAH2 overexpression could preserve endothelial cells from the inhibition of homocysteine. These results provide new insight into the elucidation of the mechanism and potential therapeutic approach for endothelial dysfunction induced by homocysteine.

Homocysteine is a sulfhydryl-containing amino acid derived from methioninemetabolism that is dependent on folic acid (vitamin B9), vitamin B12 and B6 as cofactors. Accordingly, deficiencies of these vitamins have also been shown to elevate plasma total homocysteine leading to endothelial dysfunction [20], and supplement of these vitamins is capable of lowering or normalizing plasma homocysteine levels [21]. However, increasing evidence demonstrates that supplementations of B vitamins and/or folic acid are not sufficient to improve vascular endothelial dysfunction and even produce adverse cardiovascular effects in animals and humans with hyperhomocysteinemia [4-8, 22]. Therefore such treatments are no longer recommended. 
Endothelial dysfunction, characterized by impairment of endothelium-dependent vasodilatation or endothelium-derived nitric oxide (NO) synthesis, plays a crucial role in pathophysiological process of hyperhomocysteinemia-induced cardiovascular diseases $[23,24]$. ADMA has emerged as a key factor for homocysteine-associated endothelial dysfunction $[2,4,10,13-15]$. The present study confirmed that homocysteine treatment significantly enhanced ADMA accumulation and subsequently suppressed NOS activity and NO generation in cultured endothelial cells. Similar increase of ADMA accumulation induced by homocysteine was found not only in cultured endothelial cells [15] and neurons [25], but also in animals with endothelial dysfunction [2] and patients with atherosclerosis [10,13]. These results indicate that ADMA is a mediator of diminishing NO bioavailability induced by homocysteine.

The mechanisms underlying homocysteine-induced endogenous ADMA accumulation are not fully understood. Although previous study reported that the inhibition of DDAH activity contributed to homocysteine-induced ADMA accumulation in endothelial cells ${ }^{15}$, it is still unknown whether suppressed DDAH2 expression contributes to the inhibition of DDAH activity and accumulation of endogenous ADMA induced by homocysteine in endothelial cells, because the DDAH2 and DDAH1 expression or transcription were not simultaneously examined in previous studies [2, 4, 10, 13-15, 24]. The present study provides the evidence that the suppression of DDAH2 expression is a primary cause for homocysteineinduced impairments of DDAH/ADMA/NOS/NO pathway in endothelial cells. This study demonstrated that homocysteine markedly suppressed DDAH2 transcription and expression without affecting DDAH1, resulting in the decrease of DDAH activity, increase of endogenous ADMA accumulation, inhibition of NOS activity and NO generation in endothelial cells. Similar findings have been made by other investigators in hearts of dogs with congestive heart failure [26] and in lungs of rats with pulmonary hypertension [27]. Homocysteineinduced oxidation stress might be implicated in the suppression of DDAH transcription or expression, because DDAH is a redox-sensitive enzyme resulting from a critical sulfhydryl group within its catalytic site [16]. Taken together, these results indicate that suppressed expression of DDAH2 rather than DDAH1 contributes to inhibition of DDAH activity and NO synthesis induced by homocysteine in endothelial cells.

Given that suppressed DDAH2 expression plays the determinant role in the endothelial dysfunction associated with homocysteine and there is no effective pharmacological agent to protect against homocysteine-induced impairments of DDAH/ADMA/NOS/NO pathway, the endothelial cell line of DDAH2 overexpressing was constructed and used to investigate whether DDAH2 overexpression could resist the impairment induced by homocysteine. The DDAH2-transfected endothelial cells displayed apparent enhancement of DDAH2 transcription and expression compared with untransfected cells, indicating that the endothelial cell line of DDAH2 overexpression was successfully constructed. This study further demonstrated that DDAH2 overexpression could prevent the suppression of DDAH activity, accumulation of endogenous ADMA, inhibition of NOS activity and NO synthesis in endothelial cells treated with homocysteine. These results were corroborated by previous reports that silencing DDAH2 but not DDAH1 expression with siRNA given intravenously to rats significantly inhibited vascular endothelium-dependent relaxation response to acetylcholine [28] and that DDAH2 overexpression remarkably attenuated angiotensin IIinduced increase of plasma ADMA, vascular injury and cardiac oxidative stress in DDAH2 transgenic mice [29]. On the contrary, overexpression of DDAH1 did not protect mice with dietary hyperhomocysteinemia from endothelial dysfunction [17]. The potential explanations for this discrepancy could be that DDAH2 is the predominantly isoform in endothelial cells on the one hand and that DDAH2 possesses some ADMA-independent protective effects on vascular injury of homocysteine on the other hand [29]. Collectively, these results indicate that the acceleration of ADMA degradation by DDAH2 overexpression is an adequate strategy to preserve NOS activity and NO synthesis or endothelial function in hyperhomocysteinemia. 
In order to evaluate the harm to endothelial cells by homocysteine, the activity of LDH in culture medium was measured to reflect the cell viability or degree of cell injury in the present study. Results showed that DDAH2 overexpression markedly attenuated homocysteineinduced enhance of LDH activity in the culture medium of endothelial cells, suggesting DDAH2 overexpression could preserve endothelial cells from the injury of homocysteine. Previous study has also demonstrated that DDAH2 overexpression could decline angiotensin II-induced endothelial cells injury [29]. These results implied that the protection of DDAH2 overexpression against homocysteine-induced cell injury might contribute to preservation of NO synthesis in endothelial cells.

In summary, the present study demonstrated for the first time that suppressed DDAH2 expression contributed to homocysteine-induced changes in DDAH activity, endogenous ADMA accumulation, NOS activity and NO synthesis in cultured endothelial cells. Overexpression of DDAH2 could effectively attenuate these impairments of DDAH/ ADMA/NOS/NO pathway induced by homocysteine. Therefore, DDAH2 may be a promising target for the treatment of endothelial dysfunction under hyperhomocysteinemia, and therapeutic manipulation of DDAH2 expression may also represent an effectively strategy for preservation endothelial NO synthesis from impairment of homocysteine.

\section{Acknowledgements}

This study was supported by grants from the Natural Science Research Foundation of China (30271507, 30873062 \& 81170778).

\section{Reference}

1 Ceperković Z: The role of increased levels of homocysteine in the development of cardiovascular diseases. Med Pregl 2006;59:143-147.

- Fu YF, Xiong Y, Guo Z: A reduction of endogenous asymmetric dimethylarginine contributes to the effect of captopril on endothelial dysfunction induced by homocysteine in rats. Eur J Pharmacol 2005;508:167-175.

- 3 Lan TH, Xu ZW, Wang Z, Wu YL, Wu WK, Tan HM: Ginsenoside Rb1 prevents homocysteine-induced endothelial dysfunction via PI3K/Akt activation and PKC inhibition. Biochem Pharmacol 2011;82:148-155.

4 Sydow K, Schwedhelm E, Arakawa N, Bode-Boger SM, Tsikas D, Hornig B, Frolich JC, Boger RH: ADMA and oxidative stress are responsible for endothelial dysfunction in hyperhomocyst(e)inemia: effects of L-arginine and B vitamins. Cardiovasc Res 2003;57:244-252.

-5 Woodman RJ, Celermajer DE, Thompson PL, Hung J: Folic acid does not improve endothelial function in healthy hyperhomocysteinaemic subjects. Clin Sci (Lond) 2004;106:353-258.

6 Pan Y, Guo LL, Cai LL, Zhu XJ, Shu JL, Liu XL, Jin HM: Homocysteine-lowering therapy does not lead to reduction in cardiovascular outcomes in chronic kidney disease patients: a meta-analysis of randomised, controlled trials. Br J Nutr 2012:108:400-407.

7 Ye X, Liu X: Summaries of nursing care-related systematic reviews from the Cochrane library: homocysteinelowering interventions for preventing cardiovascular events. J Cardiovasc Nurs 2011;26:168-169.

-8 Bønaa KH, Njølstad I, Ueland PM, Schirmer H, Tverdal A, Steigen T, Wang H, Nordrehaug JE, Arnesen E, Rasmussen K, NORVIT Trial Investigators: Homocysteine lowering and cardiovascular events after acute myocardial infarction. N Engl J Med 2006;354:1578-1588.

-9 Ito A, Tsao PS, Adimoolam S, Kimoto M, Ogawa T, Cooke JP: Novel mechanism for endothelial dysfunction: dysregulation of dimethylarginine dimethylaminohydrolase. Circulation 1999;99:3092-3095.

10 Stühlinger MC, Oka RK, Graf EE, Schmölzer I, Upson BM, Kapoor O, Szuba A, Malinow MR, Wascher TC, Pachinger 0, Cooke JP: Endothelial dysfunction induced by hyperhomocyst(e)inemia: role of asymmetric dimethylarginine. Circulation 2003;108:933-938. 


\section{Cellular Physiology $\quad$ Cell Physiol Biochem 2012;30:1413-1422 and Biochemistry

11 Kajimoto H, Kai H, Aoki H, Yasuoka S, Anegawa T, Aoki Y, Ueda S, Okuda S, Imaizumi T: Inhibition of eNOS phosphorylation mediates endothelial dysfunction in renal failure: new effect of asymmetric dimethylarginine. Kidney Int 2012;81:762-768.

12 Perticone F, Sciacqua A, Maio R, Perticone M, Galiano Leone G, Bruni R, Di Cello S, Pascale A, Talarico G, Greco L, Andreozzi F, Sesti G: Endothelial dysfunction, ADMA and insulin resistance in essential hypertension. Int J Cardiol 2010;142:236-241.

13 Isıklar 00, Barutcuoğlu B, Kabaroglu C, Mutaf I, Ozmen D, Bayındır O, Zoghi M, Uluer H: Do cardiac risk factors affect the homocysteine and asymmetric dimethylarginine relationship in patients with coronary artery diseases? Clin Biochem 2012;45:1325-1330.

14 Schwedhelm E, Xanthakis V, Maas R, Sullivan LM, Schulze F, Riederer U, Benndorf RA, Böger RH, Vasan RS: Asymmetric dimethylarginine reference intervals determined with liquid chromatography-tandem mass spectrometry: results from the Framingham offspring cohort. Clin Chem 2009;55:1539-1545.

15 Stühlinger MC, Tsao PS, Her JH, Kimoto M, Balint RF, Cooke JP: Homocysteine impairs the nitric oxide synthase pathway: role of asymmetric dimethylarginine. Circulation 2001;104:2569-2575.

16 Hong L, Fast W: Inhibition of human dimethylarginine dimethylaminohydrolase-1 by S-nitroso-Lhomocysteine and hydrogen peroxide. Analysis, quantification, and implications for hyperhomocysteinemia. J Biol Chem 2007;282:34684-34692.

17 Rodionov RN, Dayoub H, Lynch CM, Wilson KM, Stevens JW, Murry DJ, Kimoto M, Arning E, Bottiglieri T, Cooke JP, Baumbach GL, Faraci FM, Lentz SR: Overexpression of dimethylarginine dimethylaminohydrolase protects against cerebral vascular effects of hyperhomocysteinemia. Circ Res 2010;106:551-558.

18 Lu CW, Xiong Y, He P: Dimethylarginine dimethylaminohydrolase-2 overexpression improves impaired nitric oxide synthesis of endothelial cells induced by glycated protein. Nitric. Oxide 2007;16:94-103.

19 Yin QF, Fu SH, He P, Xiong Y: Dimethylarginine dimethylaminohydrolase inhibition and asymmetric dimethylarginine accumulation contribute to endothelial dysfunction in rats exposed to glycosylated protein: effects of aminoguanidine. Atherosclerosis 2007;190:53-61.

-20 Fabian E, Kickinger A, Wagner KH, Elmadfa I: Homocysteine and asymmetric dimethylarginine in relation to B vitamins in elderly people. Wien Klin Wochenschr 2011;123:496-501.

-21 Xu T, Zhang XW, Qu XK, Ye HY, Huang XB, Zhang XP, Hou SK, Wang XF: Treatment of hyperhomocysteinemia and endothelial dysfunction in renal transplant recipients with B vitamins in the Chinese population. J Urol 2008;179:1190-1194.

22 Song Y, Cook NR, Albert CM, Van Denburgh M, Manson JE: Effect of homocysteine-lowering treatment with folic Acid and B vitamins on risk of type 2 diabetes in women: a randomized, controlled trial. Diabetes 2009;58:1921-1928.

23 Bellamy MF, McDowell IF, Ramsey MW, Brownlee M, Bones C, Newcombe RG, Brownlee M, Bones C, Newcombe RG, Lewis MJ: Hyperhomocysteinemia after an oral methionine load acutely impairs endothelial function in healthy adults. Circulation 1998;98:1848-1852.

24 Abdulle AM, Pathan JY, Moussa N, Gariballa S: Association between homocysteine and endothelial dysfunction markers in stroke disease. Nutr Neurosci 2010;13:2-6.

-25 Selley ML: Homocysteine increases the production of asymmetric dimethylarginine in cultured neurons. J Neurosci Res 2004;77:90-93.

26 Chen Y, Li Y, Zhang P, Traverse JH, Hou M, Xu X, Kimoto M, Bache RJ: Dimethylarginine dimethylaminohydrolase and endothelial dysfunction in failing hearts. Am J Physiol Heart Circ Physiol 2005;289:H2212- H2219.

-27 Pullamsetti S, Kiss L, Ghofrani HA, Voswinckel R, Haredza P, Klepetko W, Voswinckel R, Haredza P, Klepetko W, Aigner C, Fink L, Muyal JP, Weissmann N, Grimminger F, Seeger W, Schermuly RT: Increased levels and reduced catabolism of asymmetric and symmetric dimethylarginines in pulmonary hypertension. FASEB J 2005;19:1175-1177.

28 Wang D, Gill PS, Chabrashvili T, Onozato ML, Raggio J, Mendonca M, Dennehy K, Li M, Modlinger P, Leiper J, Vallance P, Adler O, Leone A, Tojo A, Welch WJ, Wilcox CS: Isoform-specific regulation by N(G),N(G)dimethylarginine dimethylaminohydrolase of rat serum asymmetric dimethylarginine and vascular endothelium-derived relaxing factor/NO. Circ Res 2007;101:627-35.

29 Hasegawa K, Wakino S, Tatematsu S, Yoshioka K, Homma K, Sugano N, Kimoto M, Hayashi K, Itoh H: Role of asymmetric dimethylarginine in vascular injury in transgenic mice overexpressing dimethylarginie dimethylaminohydrolase2. Circ Res 2007;101:e2-e10. 